\title{
BMJ Open Access to care for people with alcohol use disorder in France: a mixed-method cross-sectional study protocol (ASIA)
}

\author{
Marie Costa, ${ }^{1,2}$ Fabienne Marcellin, ${ }^{1,2}$ Marion Coste, ${ }^{1,2}$ Tangui Barré, ${ }^{1,2}$ \\ Sandra Nordmann, ${ }^{1,2}$ Marion Mora, ${ }^{1,2}$ Gwenaëlle Maradan,, ${ }^{1,2}$ Marc Tanti, ${ }^{1,2,3}$ \\ Christophe Cutarella, ${ }^{4}$ Danielle Casanova, ${ }^{5}$ Sabrina Levy-Bellaiche, ${ }^{6}$ \\ Pierre Polomeni, ${ }^{7}$ Nicolas Simon, ${ }^{1,2}$ Perrine Roux, ${ }^{1,2}$ Maria-Patrizia Carrieri ${ }^{1,2}$
}

To cite: Costa M, Marcellin F, Coste $\mathrm{M}$, et al. Access to care for people with alcohol use disorder in France: a mixedmethod cross-sectional study protocol (ASIA). BMJ Open 2018;8:e24669. doi:10.1136/ bmjopen-2018-024669

- Prepublication history for this paper is available online. To view these files please visit the journal online (http://dx.doi org/10.1136/bmjopen-2018024669).

Received 7 June 2018 Revised 25 July 2018 Accepted 22 August 2018

Check for updates

(C) Author(s) (or their employer(s)) 2018. Re-use permitted under CC BY-NC. No commercial re-use. See rights and permissions. Published by BMJ.

For numbered affiliations see end of article.

Correspondence to

Dr Marie Costa;

mariecosta1212@gmail.com

\section{ABSTRACT}

Introduction Alcohol use disorder (AUD) is a major public health concern worldwide. In France, only $10 \%$ of people with AUD (PWAUD) receive medical care. General practitioners (GP) are one of the main entry points for AUD care. The present ongoing study, entitled ASIA (Access to Care and Indifference toward Alcohol, Accès aux Soins et Indifference à l'Alcool in French), aims to improve knowledge about factors associated with access to care for AUD by exploring related GP and PWAUD practices, experiences and perceptions.

Methods and analysis The ASIA project is an ongoing cross-sectional multisite study based on a complementary mixed-method approach (quantitative and qualitative) using a convergent parallel design. The double-perspective design of the study will enable us to collect and compare data regarding both PWAUD and GP points of view. For the PWAUD quantitative study, 260 PWAUD will be interviewed using a telephone-based questionnaire. For the qualitative study, 36 PWAUD have already been interviewed. The GP quantitative study will include $100 \mathrm{GP}$ in a 15 min survey. Fifteen GP have already participated in semistructured interviews for the qualitative study. Logistic regression will be used to identify predictors for access to care. With respect to data analyses, qualitative interviews will be analysed using semantic analysis while quantitative logistic regression will be used for quantitative interviews. Ethics and dissemination This study was approved by the CNIL (French National Commission on Informatics and Liberties) (approval reference number: C16-10, date of approval: 17 July 2017), the CCTIRS (Advisory Committee on Information Processing in Material Research in the Field of Health) and the CEEl (Evaluation and Ethics Committee) (approval reference number: 16-312, date of approval: 8 July 2016) of INSERM (French National Institute of Health and Medical Research). Results from ASIA will be disseminated in peer-reviewed publications, conference presentations, reports and in a PhD thesis.

\section{INTRODUCTION}

Alcohol use disorder (AUD) is a major health and social concern and is responsible for approximately 3.3 million deaths (or $5.9 \%$ of all global deaths) annually. ${ }^{1}$ It is estimated

\section{Strengths and limitations of this study}

- The originality of this study is that it cross-analyses general practitioner (GP) and people with alcohol use disorder (PWAUD) data regarding a common issue. Its results will be very useful for improving AUD management in primary care and, consequently, for improving access to care for PWAUD in general.

- The major strength of this study is its mixed use of qualitative and quantitative data, which enables us to collect subjective data-such as perceptions—as well as data on measurable variables, both elements being involved in the patient's AUD care trajectory.

- Another strength is the recruitment of both PWAUD involved and PWAUD not involved in AUD care, so that barriers as well as levers to access to care can be identified.

- The study population with AUD enrolled in the study may not be completely representative of the general population with AUD in France, and data may need appropriate weighting during analysis.

that AUD contributes to over 200 diseases and injury conditions, especially liver cirrhosis and cancer. ${ }^{1}$ The prevalence of alcohol dependence in Europe has been evaluated at $6.4 \%$ among men and $1.2 \%$ among women. ${ }^{2}$ Only $10 \%$ of people concerned by AUD receive medical care for AUD in France. ${ }^{3}$

According to a report on alcohol use, published by the French Observatory on Drugs and Drug Addiction (OFDT) in $2014,{ }^{45} 10 \%$ of people interviewed in the country $(n=15635)$ reported daily alcohol consumption. A report published in $2015^{6}$ estimated the annual external cost of alcohol abuse at $€ 114,399$ billion, in terms of lost lives, reduced quality of life and production losses.

In France, it is difficult to obtain accurate figures on care for AUD due to the different AUD management entry points ${ }^{7}$ (specialised centres, general practitioners (GP), hospitals, 
associations), but the proportion of people with AUD (PWAUD) linked to medical care for this disorder is definitely small. $^{8}$

Although medical care for substance use disorders is easily accessible in Care, Prevention, and Support Centre for Addiction (CSAPA), GP constitute the main first line of care for AUD screening. Primary healthcare provided by GP is the first-choice option for preventing, screening and managing AUD and its consequences. Indeed, in addition to being the first point of contact, GP are numerous and provide comprehensive and coordinated care. ${ }^{910}$

Depending on the severity of the disorder, different psychosocial approaches can be used to help PWAUD reduce or stop alcohol, including motivational interviews, mindfulness interventions, social skills training and behavioural self-control training. ${ }^{11}$ In addition, five different pharmacological treatments can be prescribed: acamprosate, disulfiram, naltrexone, nalmefene and baclofen. ${ }^{12}$ Acamprosate and disulfiram are prescribed to help maintain abstinence in people who have already stopped drinking. Naltrexone is approved for abstinence maintenance, but has also been used off-label to reduce consumption. ${ }^{13}$ Nalmefene is prescribed to reduce consumption as it reduces craving. Baclofen is also used to reduce craving, but unlike the other four drugs, which are legally available in France, it can only be prescribed off-label, as part of France's regulatory drug evaluation framework (called 'Temporary Recommendation Use (TRU)'). A review published in 2016 concluded that all five treatments show different safety profiles and must be adapted to each patient's alcohol consumption goal and individual profile. ${ }^{14}$ Another review reported that all five treatments are still underused and that barriers to their prescription need to be investigated. ${ }^{15}$

It is important to note that we are in a transitional period between one paradigm and another. More specifically, alcohol-related risk reduction, including controlled drinking (CD), is becoming an acceptable therapeutic goal for caregivers and patients ${ }^{16}$; until very recently, the standard of care for AUD was based on stopping consumption, maintaining abstinence, preventing chronic complications related to excessive alcohol consumption and managing withdrawal symptoms. The licensing of nalmefene and the prescription of baclofen within France's TRU framework confirm this paradigm shift. ${ }^{17}$ For many patients who might not be immediately ready for total abstinence, reducing consumption may constitute a realistic achievable goal. ${ }^{18}$

Lack of awareness of having AUD and apprehension towards total alcohol abstinence are two important barriers to treatment seeking. ${ }^{19}$ It is possible that a lack of knowledge about the different AUD therapeutic options currently available ${ }^{20}$ also constitutes a barrier.

Given this dynamic context, an in-depth evaluation of access to care for PWAUD in France would seem necessary. The present study, Accès aux Soins et Indifference à l'Alcool (ASIA), aims to improve knowledge about factors associated with seeking, receiving and providing care for AUD by exploring related GP and PWAUD practices, experiences and perceptions.

\section{General study design}

ASIA is an ongoing multisite cross-sectional study which started in France in 2016. It aims to explore barriers to and facilitators of access to care for PWAUD in France, and to provide a better understanding of the individual and contextual factors associated with the currently poor level of access to care for those who wish to stop or reduce their alcohol consumption. The study uses a mixed approach which comprises (1) a qualitative study and (2) a quantitative study for two populations: PWAUD (1) and GP (2).

The complementary mixed-method approach (quantitative and qualitative) implemented here uses a convergent parallel design. ${ }^{21}$ This type of study design provides a more comprehensive view of a phenomenon, as it separately cross-analyses data collected concomitantly using these two study approaches from each of two different studies (in our situation PWAUD and GP). For the present work, comparing data from the resulting four substudies will shed greater light on the mechanisms leading or not to AUD care.

\section{METHODS AND ANALYSIS Objectives}

The specific objectives of the study are presented below. Relationship between project objectives and study components are resumed in table 1.

1. Identify sociodemographic characteristics and health experiences associated with access to care (PWAUD).

2. Determine sociodemographic and professional characteristics associated with AUD management and screening, acceptance of CD and AUD pharmacological treatment prescription (GP).

3. Assess whether barriers found in other studies were relevant in the current French context (PWAUD and GP).

4. Identify other barriers and levers which could have been missed in the quantitative study (GP and PWAUD).

5. Illustrate and examine in depth the findings of the quantitative study (GP and PWAUD).

\section{Definition of AUD}

The main tool used by the WHO to measure alcohol consumption is the Alcohol Use Disorders Identification Test (AUDIT) ${ }^{22}$ This 10 -item questionnaire provides an alcohol consumption score from 0 to 40 . Scores between 8 (7 for women) and 15 suggest hazardous alcohol consumption, 16 and 19 harmful alcohol consumption and $>20$ alcohol dependence. ${ }^{15}$ We chose to include only people with a score $>15$, because above this, medical care is recommended. ${ }^{11}$ 


\begin{tabular}{|c|c|c|c|c|}
\hline & $\begin{array}{l}\text { PWAUD } \\
\text { qualitative } \\
\text { study }\end{array}$ & $\begin{array}{l}\text { PWAUD } \\
\text { quantitative } \\
\text { study }\end{array}$ & $\begin{array}{l}\text { GP } \\
\text { qualitative } \\
\text { study }\end{array}$ & $\begin{array}{l}\text { GP } \\
\text { quantitative } \\
\text { study }\end{array}$ \\
\hline $\begin{array}{l}\text { (2) Determine sociodemographic and professional characteristics } \\
\text { associated with AUD management and screening, acceptance of CD } \\
\text { and pharmacological treatment prescription (GP). }\end{array}$ & & & & $X$ \\
\hline $\begin{array}{l}\text { (3) Assess whether barriers found in other studies were relevant in the } \\
\text { current French context (PWAUD and GP). }\end{array}$ & & $x$ & & $x$ \\
\hline $\begin{array}{l}\text { (4) Identify other barriers and levers which could have been missed in } \\
\text { the quantitative study (GP and PWAUD). }\end{array}$ & $X$ & & $x$ & \\
\hline $\begin{array}{l}\text { (5) Illustrate and examine in depth the findings of the quantitative } \\
\text { study (GP and PWAUD). }\end{array}$ & $x$ & & $x$ & \\
\hline
\end{tabular}

AUD, alcohol used isorder; CD, controlled drinking; GP, general practitioner; PWAUD, people with alcohol used isorder.

\section{Definition of care}

In this study, we decided to define 'receiving care' as follows:

- Receiving non-pharmacological therapeutic interventions from a healthcare professional to reduce or stop alcohol consumption

and/or

- Participating in an alcohol-related support group (such as Alcoholics Anonymous) and/or:

- Taking one of the five approved AUD pharmacological drugs

\section{Patient and public involvement statement}

Neither patients nor the general public were involved in the design of this study.

In order to respect patient confidentiality, we will not keep participants' contact information. Consequently, the results of the study will not be personally disseminated to participants. Participants are informed in the consent form that if they wish, they can contact the main investigator to obtain the study results.

\section{Sampling strategy and data collection}

As of May 2018, data collection for the qualitative substudies has already been performed for the PWAUD and GP. Analysis of qualitative GP data has also been completed. More in-depth details can be found in this section.

\section{PWAUD population}

Inclusion criteria

For both substudies (ie, quantitative and qualitative), the following inclusion criteria are used: aged over 18 , French speaking and AUDIT score $>15$.

Qualitative substudy

Recruitment and data collection

From June 2016 to May 2017, 36 patients were recruited in four medical services: the Saint-Barnabe substance disorder clinic in Marseille, two CSAPA (Care, Prevention, and Support Centre for Addiction) in Avignon and Nîmes and the CISIH (Information and Care Centre for Human Immunodeficiency) in Saint-Marguerite Hospital in Marseille (patients recruited through this service were not already receiving AUD care at enrolment). Medical staff informed their patients of the study and introduced potential participants to the study investigator.

After providing information about the study, the study investigator performed a face-to-face interview in a closed office to ensure confidentiality. The interview was semistructured and conducted according to the guide described in table 2.

Interviews lasted between 30 and $75 \mathrm{~min}$ and were recorded. Recordings were transcribed using word processing software. Transcripts of interviews were not returned to PWAUD participants for comments or correction. Only the qualitative substudy investigator has access to these records. Information concerning participants' confidentiality and anonymity is presented in the Ethics and Dissemination section.

\section{Data analysis}

The qualitative data for the PWAUD interview corpus has yet to be analysed (as of June 2018). The text analysis software Iramuteq (Interface de R pour les Analyses Multidimensionnelles de Textes et de Questionnaires) (V.0.7 Alpha 2) will be used. Iramuteq provides different processing and statistical analysis options for produced texts and ensures accurate analyses for qualitative health research.

Descending hierarchical classification will be performed, whereby calculations are performed on the concurrence of words in the text. ${ }^{23}$ The results come in the form of speech classes that are statistically over-represented in the segments gathered in the classes. Each of the lexical classes is described in detail by the lexicon that defines it, the characteristic segments that represent it, and the associated variables. ${ }^{24}$ 
Table 2 Semistructured PWAUD interview guide

\begin{tabular}{|c|c|}
\hline \multicolumn{2}{|c|}{ Qualitative substudy for PWAUD } \\
\hline $\begin{array}{l}\text { Standard data } \\
\text { collected }\end{array}$ & $\begin{array}{l}\text { Audit score } \\
\text { Enrolment site } \\
\text { Year of birth } \\
\text { Gender } \\
\text { Personal situation (eg, living in a couple, having children, etc) } \\
\text { Professional situation (eg, employment status) } \\
\text { Substance use (Yes/No, and if applicable, consumption frequency) }\end{array}$ \\
\hline
\end{tabular}

$\begin{array}{ll}\text { Semistructured PWAUD interview guide } \\ \text { Opening question } \\ \text { You are experiencing difficulties with your alcohol consumption. I imagine it is difficult to deal with that. } \\ \text { Could you tell me about your experience with alcohol since you started drinking, including, if applicable, } \\ \text { your experience with health professionals for this specific problem? } \\ \begin{array}{l}\text { If the interviewee } \\ \text { does not mention }\end{array} \text { How long have you been drinking, how did it start? } \\ \text { these topics } & \text { Who have you talked to about your drinking problem? } \\ \text { spontaneously, } & \text { Have you talked about it with your family physician or another physician? } \\ \text { the interviewer } & \text { What do you think prevents you from reducing or stopping your alcohol consumption? } \\ \text { must do so. } & \text { What steps have you taken to try to change your consumption? (treatment, consultation with } \\ & \text { specialists, alternative medicines, etc) } \\ & \text { Have you ever taken medication to stop drinking? Which medication(s) precisely? } \\ & \text { Have you looked for information concerning treatments to stop or reduce alcohol consumption? } \\ & \text { Do you visit medical websites and/oronline forums? Does this help you? How? }\end{array}$

PWAUD, people with alcohol used isorder.

Iramuteq descending hierarchical classification includes five stages:

1. The full corpus is divided into text segments composed of 40 words (by default).

2. Lemmatisation: grouping of the inflected forms of a word so they can be analysed as a single item (verbs in the infinitive, nouns in the singular and adjectives in the masculine singular) (Unlike English, the French language has masculine and feminine endings for adjectives).

3. Definition of a contingency table of 'analysable' reduced forms and text segments.

4. Top-down hierarchical classification analysis: performed to obtain stable classes and significant associated words (tested by $\chi^{2}$ ).

5. Production of class description to enable interpretation.

\section{Quantitative substudy}

\section{Recruitment and data collection}

Recruitment started in September 2017 and is ongoing (as of June 2018). PWAUD are recruited in several different medical services such as CSAPA, clinics, hospitals, addiction care services and ELSA (translated from French as 'Team for Linkage to Addiction Care', ELSA is an organisation of trained addiction care professionals, created in 2000 to increase screening and care for patients with AUD in hospitals. Patients recruited through ELSA are not yet receiving AUD care at enrolment).

Medical staff inform their patients of the study and provide them with the consent form. They collect the phone number of patients who agree to participate and provide related information to the investigators.

Participants are then contacted for a phone-based interview. Computer-assisted interviews are conducted by trained investigators and answers are collected using Sphinx software (V.IQ 2).

Interviews follow a questionnaire based on the framework detailed in table 3 . This questionnaire was built by exploring the literature on similar topics.

\section{Statistical considerations}

Collected variables considered to be potentially associated with access to care include sociodemographic factors, characteristics of family members (with AUD or not), drinking patterns, perceived stigma and perception about treatment for AUD (table 3).

In order to calculate the sample size, we want to over-represent those who have received care for AUD by a factor of 2 in order to compare possible 'care subgroups'. A sample size of 110 versus 55 will allow us to highlight a strength of association with an OR 2.77 between potential correlates and receiving care for AUD (alpha $=5 \%$ and a Power $=80 \%$ ).

Data will be analysed with STATA (Stata Statistical Software: Release 14. College Station, Texas, USA: StataCorp LP). In order to control for possible recruitment biases, the sociodemographic characteristics of PWAUD will be compared between individuals recruited in the ASIA study and individuals in the French general population identified with AUD in the 2016 Health Barometer 


\begin{tabular}{|c|c|c|}
\hline $\begin{array}{l}\text { Section } \\
\text { number }\end{array}$ & Main theme & Specific themes \\
\hline 1 & General information & $\begin{array}{l}\text { Age, gender, family situation, educational status, income, employment status, quality } \\
\text { of housing, receiving ordinary healthcare, access to transportation, internet access. }\end{array}$ \\
\hline 2 & Alcohol consumption & $\begin{array}{l}\text { Craving level, health issues related to alcohol consumption, withdrawal symptoms, } \\
\text { alcohol consumption perceptions }\end{array}$ \\
\hline 3 & $\begin{array}{l}\text { Substances use other than } \\
\text { alcohol }\end{array}$ & Tobacco, opioids, benzodiazepines, cocaine, synthetic drugs \\
\hline 4 & $\begin{array}{l}\text { Experiences and perceptions } \\
\text { related to alcohol consumption }\end{array}$ & Feelings, discrimination, drinking environment (place, peers) \\
\hline 5 & $\begin{array}{l}\text { AUD aims concerning personal } \\
\text { alcohol consumption }\end{array}$ & (eg, abstinence, reduction, etc) \\
\hline 6 & Care received & $\begin{array}{l}\text { Having a regular GP, quality of relationship with regular GP, receiving/having received } \\
\text { care (in the } 3 \text { years prior to enrolment), having already sought AUD care through } \\
\text { regular GP or in general, and, if applicable, reasons for not having sought AUD care. }\end{array}$ \\
\hline 7 & $\begin{array}{l}\text { Methods used to stop or } \\
\text { reduce alcohol consumption }\end{array}$ & $\begin{array}{l}\text { Medical methods, alternative therapies, association support. For each method, } \\
\text { participants are asked if it was/is helpful and if it is ongoing. }\end{array}$ \\
\hline $8 / 9$ & Pharmacological treatments & $\begin{array}{l}\text { Pharmacological treatments: Question } 8 \text { is designed for PWAUD who have already } \\
\text { had at least one experience with pharmacological treatment, while question } 9 \text { is } \\
\text { for people who have never taken any pharmacological treatment. For each of the } \\
\text { five prescribed pharmacological treatments for maintaining abstinence or reducing } \\
\text { alcohol consumption, participants are asked (1) if they have heard of it (if applicable } \\
\text { where/from whom), (2) if they have taken the treatment (if applicable, who prescribed } \\
\text { it to them), (3) reasons for deciding to take or not to take this treatment, (4) the } \\
\text { treatment's efficacy and (5) (if appropriate) their personal opinion about the causes } \\
\text { for failure using this treatment. }\end{array}$ \\
\hline
\end{tabular}

AUD, alcohol used isorder; GP, general practitioner; PWAUD, people with alcohol use d isorder.

Survey, which was conducted by the Health Prevention and Education National Institute (INPES). The results obtained will be used to decide if a weighting procedure is needed to make our data more representative of PWAUD living in France.

The main correlates of access to care for PWAUD, including potential barriers and levers, will be identified using univariate and multivariable logistic regression models, the outcome being 'Having access to care for AUD in the three previous years medical care for AUD (yes/no)'. In order to control for heterogeneity depending on the type of care accessed by PWAUD, the outcome will also be expressed as a categorical ordinal variable and multinomial logistic regression will be used. Possible missing data in the outcomes can be managed using selection models (such as the Heckman model). ${ }^{25}$

Sensitivity analyses will be performed on specific subgroups (eg, those never treated vs those receiving pharmacological treatment for AUD) to verify results' robustness.

\section{GP population}

\section{Inclusion criteria}

For both substudies (ie, quantitative and qualitative), the following criteria are used: working as a GP and following at least three PWAUD in the 3 years prior to the interview (even if they did not consult for AUD).

\section{Qualitative study}

Recruitment and data collection

From December 2016 to August 2017, 15 GP were recruited from a GP network. Recruitment took place using a 'snowball method' as follows: a member of the study's research team first provided the study investigator with the contact information for two GP, who were then contacted by email. Both agreed to participate. These first participants were then asked for two other colleagues' emails, so that they, too, could be invited, and so on. Information about the study and the consent form to be completed were sent to all GP by email.

Interviews took place in GP offices or were performed over the telephone and were recorded in both cases. The interviews were semistructured and conducted according to the guide described in table 4 .

\section{Data analysis}

Data analysis has been completed. For the GP interview corpus (10 hours), a manual sequenced thematic analysis $^{26}$ was performed. To ensure the results' reliability, four transcribed interviews were randomly selected, read repeatedly, analysed, coded and then categorised separately by the main investigator and her supervisor. They then discussed their respective findings together to identify discourse themes. The main investigator then conducted the initial coding of all 15 transcribed 
Table 4 Semistructured GP interview guide

Qualitative substudy among GP

Standard data collected Year of birth

Gender

Beginning date of professional practice

Workplace category (urban, rural or semirural)

Semistructured GP interview guide

Opening question Can you tell me about your experience with patients with alcohol use disorder, especially how you handle them?

If the interviewee does $\quad$ Are you currently following patients with alcohol use disorder?

not mention these topics How do you screen for alcohol use disorder? Do you use a specific scale or test?

spontaneously, the Do you treat patients by yourself for substance abuse or do you refer them to a colleague or a interviewer must do so: specialised centre?

- Do you prescribe pharmacological treatments to help with the suppression/reduction of alcohol consumption? Which ones?

- What motivates this choice of treatment?

- Do you think it is possible to stop drinking without treatment?

- Do you think that abstinence is the only possible answer for people who have a drinking problem?

- Do you consider that reducing consumption is an acceptable therapeutic objective (with respect to abstinence)?

- What do you think about baclofen and nalmefene?

GP, general practitioner.

Table 5 GP questionnaire

\section{GP questionnaire}

Section
number Main theme $\quad$ Specific themes

1 General information about Gender, age, practice duration (years), number of regular patients, consultation duration GP and their practice addictology training, participation in an addictology network, opioid maintenance treatment prescription, interest in addictology, tobacco cessation management.

$2 \quad$ Alcohol consumption screening: alcohol cessation/reduction

Performs screening (yes or no, alone or with another healthcare professional and, if management applicable, which category of professional), reason for not managing patient alcohol cessation, number of patients with AUD, prescribes blood analysis to screen for AUD (yes or no), AUD spontaneous assessment (if applicable, with which tool/scale), uses a brief intervention (yes or no), knowledge of specialised alcoholism network structures (for nine different structures, GP are asked if they know the structure and if they collaborate with it).

\begin{tabular}{|c|c|c|}
\hline 3 & $\begin{array}{l}\text { AUD management (if } \\
\text { applicable) }\end{array}$ & $\begin{array}{l}\text { AUD management motivations, treatment/orientation/advice provided, pharmacological } \\
\text { treatment prescription (yes or no and, if applicable, the reason for not prescribing } \\
\text { pharmacological treatment to stop or reduce alcohol consumption), prescription of one } \\
\text { of the five pharmacological treatments indicated to stop or reduce alcohol consumption } \\
\text { (for each treatment: treatment prescription intention, prescription motivation, treatment } \\
\text { risk-benefit opinion, opinion about causes for treatment failure, opinion about causes } \\
\text { for poor adherence and treatment cessation). }\end{array}$ \\
\hline 4 & Opinion question & $\begin{array}{l}\text { 'Do you think that abstinence is the only acceptable therapeutic goal for PWAUD? (Yes, } \\
\text { no, I don't know)', and 'Do you think that CD is a realistic therapeutic goal for PWAUD? } \\
\text { (Yes, no, I don't know)'. }\end{array}$ \\
\hline
\end{tabular}

interviews according to the previously identified themes. After preliminary analysis, the coding framework was discussed and approved by all the study group members. The main investigator then conducted the final coding.

Quantitative substudy

Recruitment and data collection

Recruitment started in May 2017 and is ongoing (as of May 2018). GP are recruited randomly from the French professional phonebook. Inclusion criteria are the same as for the qualitative study. After receiving information on the study and providing consent, participants are contacted to perform the survey. Just as for the PWAUD quantitative study, computer-assisted interviews are conducted by trained investigators and answers are collected using Sphinx software (V.IQ2). Interviews follow a questionnaire based on the guide detailed in table 5 . 
The questionnaire was built by exploring the literature on similar topics.

In order to calculate the sample size, we assumed a $50 \%$ prevalence of GP not providing AUD. In order to be able to identify an OR equal to 3.5 when comparing the risk of not providing care when being exposed or non-exposed to a potential correlate, with $80 \%$ power and a 0.05 alpha risk, we calculated that we need to recruit at least 46 GP who provide AUD care and 46 who do not. We rounded this total to 50 and 50 (100 GP in total).

\section{Statistical considerations}

Outcomes and potential correlates (See table 5)

The four following outcomes will be explored:

1. Systematic AUD screening (table 5, Section 2)

2. AUD management (table 5 , Section 3 )

3. Acceptance of $\mathrm{CD}$ as a therapeutic goal (table 5, Section 4)

4. Prescription of pharmacological treatment (table 5, Section 3)

Potential variables that will be considered for analysis include demographic and professional characteristics/ practices, number of patients with AUD and perceived barriers to engaging patients in care for AUD (lack of training, patient's denial of AUD, lack of time, complexity of AUD patients' profile (ie, several concurrent psychological and physiological comorbidities).

Percentages, median and IQR will be used to describe the characteristics of the study group. In order to identify correlates of the three outcomes, we will use logistic regression models.

Potential explanatory variables of all four outcomes are described in the questionnaire outlined in table 5. Logistic regression models will be used to compute both crude and adjusted OR and their $95 \% \mathrm{CI}$ in order to obtain an estimate of the strength of the association between each explanatory variable and each outcome.

Variables with a liberal $\mathrm{p}$ value $<0.20$ will be considered eligible for the multivariable models which will be built using a backward procedure based on the likelihood ratio test $(p<0.05)$. Perceived barriers to AUD engagement in care will be eligible for the final multivariable model independently of the $p$ value obtained in the bivariable analysis, due to the high risk of confounding.

All the analysis will be performed using STATA SE/12.1.

Identifying GP who are likely to prescribe treatment for AUD and those who are not may help target future interventions to improve screening and treatment for PWAUD.

\section{DISCUSSION}

The originality of the present protocol lies in the use of the combination of a mixed-method and a 'double-perspective' design. Various studies exploring both healthcare providers' and patients' points of view have highlighted differences in expectations, priorities and perceptions of each of the two populations, and identified the need to develop patient-centred care strategies. ${ }^{27-29}$ We believe that our study will confirm these findings and bring to light some new concerns in the field of AUD care. The use of a qualitative and quantitative mixed-method approach is, in our opinion, very pertinent, as alcohol consumption is highly integrated into various sociocultural patterns and differs greatly from one context to another. ${ }^{30}$ Qualitative study approaches are especially useful to increase sociocultural understanding. ${ }^{31}$ The replication of this study would be of great value for several reasons: the use of the mixed-method approach permits an in-depth exploration of the different aspects of access to care in a specific context, and the double-perspective design leads to a greater understanding of the differences between the two populations' views and perceptions.

The use of two different qualitative analysis methods may seem questionable but can be justified by the difference between the volume of data for GP and for PWAUD. More specifically, as the PWAUD interview corpus was very large ( 35 hours), the use of a software-assisted thematic and lexical content analysis seemed an appropriate choice. As the GP qualitative data were less substantial, manual thematic analysis seemed more appropriate. Data obtained using these two methods can easily be compared and researchers aiming to reproduce this study have the choice of using one or both of these same methods to analyse qualitative data.

We believe results from ASIA will be of great use in the development of future recommendations and the updating of care guidelines for GP, an important element being clear information about AUD care networks. The ASIA study's results will be disseminated via peer-reviewed publications, conference presentations and in general public media.

\section{Ethics and dissemination}

The confidentiality and anonymity of participant data will be guaranteed for both GP and PWAUD in every step of the study; no information will be kept which could result in participants being identified. Audio-recorded interviews will be transcribed and deleted within 3 months after recording. Only the main investigator will have access to the recordings. For both populations, participation in the quantitative and/or the qualitative substudy will only occur if written consent is given after the individual has been provided with a document explaining ASIA modalities and objectives.

This study was approved by the CNIL (French National Commission on Informatics and Liberties) (approval reference number: C16-10 , d ate of approval: 17 July 2017), the CCTIRS (Advisory Committee on Information Processing in Material Research in the Field of Health) and the CEEI (Evaluation and Ethics Committee) (approval reference number: $16-312, \mathrm{~d}$ ate of approval: 8 July 2016) of INSERM (French National Institute of Health and Medical Research).

Results from ASIA will be disseminated at several levels: We plan to publish four articles in peer-reviewed 
international scientific journals covering the fields of public health, general practice and substance use disorders. We also plan to present our significant results in national and international congresses and events for professionals working within the field of AUD and health prevention.

The ASIA project will result in a $\mathrm{PhD}$ thesis, which will be defended in 2019.

A short report presenting ASIA main results will be distributed in PWAUD recruitment sites for staff and patients.

By the end of 2019, a presentation of ASIA results will be performed at the MILDECA (French inter-ministerial mission for the fight against drugs and addictive behaviours), the French government organisation which coordinates actions related to campaign against addictive behaviours. It will enable the design of recommendations to raise the awareness of GP about the necessity of improving screening and care for alcohol use disorder in their routine practice.

\section{Author affiliations}

${ }^{1}$ INSERM, IRD, SESSTIM, Sciences Economiques \& Sociales de la Santé \& Traitement de l'Information Médicale, Aix-Marseille Université, Marseille, France ${ }^{2}$ ORS PACA, Observatoire régional de la santé Provence-Alpes-Côte d'Azur, Marseille, France

${ }^{3}$ CESPA, Centre d'Epidémiologie et de Santé Publique des Armées, Marseille, France ${ }^{4}$ Clinique Saint-Barnabé, Marseille, France

${ }^{5} \mathrm{CSAPA}$, Centre de soins, d'accompagnement et de prévention en addictologie,

Arles, France

${ }^{6} \mathrm{CHU}$, Centre Hospitalier Universitaire de Nimes, Nimes, France

${ }^{7}$ APHP, Assistance Publique, Hôpitaux de Paris, Paris, France

Acknowledgements We thank all members of the ASIA Study Group. We especially thank all the physicians involved and all those who agreed to participate in the study. Finally, we thank Jude Sweeney for the English revision and editing of our manuscript.

Contributors M-PC, SN, MCosta, FM, PR, MM, TB, MCoste and GM designed the study and wrote the protocol. MCosta and M-PC managed the literature searches and formulated the research questions. MCosta wrote the first draft of the manuscript. NS, PP, CC, DC, SL-B and MT reviewed the manuscript and gave their approval. All authors contributed to and approved the current version of the manuscript.

Funding The study received external funding from the Public Health Research Institute (IRESP).

Disclaimer This work has not been published previously and is not under consideration for publication elsewhere. If accepted, this work will not be published elsewhere in English or in any other language, without the written consent of the copyright holder.

Competing interests The commercial company Ethypharm provides financial support, in the form of a salary, to author MCosta.

Patient consent Not required.

Ethics approval This study was approved by the French National Commission on Informatics and Liberties (CNIL) (approval reference number: C16-10, date of approval: 17 July 2017), the Advisory Committee on Information Processing in Material Research in the Field of Health (CCTIRS) and the Evaluation and Ethics Committee (approval reference number: 16-312, date of approval: 8 July 2016) (CEEI) of the French National Institute of Health and Medical Research (INSERM).

Provenance and peer review Not commissioned; externally peer reviewed.

Open access This is an open access article distributed in accordance with the Creative Commons Attribution Non Commercial (CC BY-NC 4.0) license, which permits others to distribute, remix, adapt, build upon this work non-commercially, and license their derivative works on different terms, provided the original work is properly cited, appropriate credit is given, any changes made indicated, and the use is non-commercial. See: http://creativecommons.org/licenses/by-nc/4.0/.

\section{REFERENCES}

1. WHO. Global status report on alcohol and health 2014, 2014

2. WHO, 2014. Regional office for Europe, alcohol fact sheet, WHO, 2014. http://www.euro.who.int/ data/assets/pdf file/0007/343744/ 2017-Alcohol-Fact-Sheet-FINAL.pdf?ua=1 (cited 23 Aug 2017).

3. Alonso J, Angermeyer MC, Bernert S, et al. Use of mental health services in Europe: results from the European Study of the Epidemiology of Mental Disorders (ESEMeD) project. Acta Psychiatr Scand Suppl 2004;420:47-54.

4. Observatoire Français des Drogues et des Toxicomanies, 2014. Synthèse thématique sur l'alcool, 2014. https://www.ofdt.fr/produitset-addictions/de-z/alcool/ (cited 23 Aug 2017).

5. Beck F, Richard J-B. La consommation d'alcool en France. La Presse Médicale 2014;43:1067-79.

6. Kopp P. Observatoire Français des Drogues et des Toxicomanies, 2015. Le coût social des drogues en France. https://www.ofdt.fr/ BDD/publications/docs/eisxpkv9.pdf (cited 25 Aug 2017).

7. Observatoire Français des Drogues et des Toxicomanies, 2017. Drogues, chiffes clés, 7ème édition. https://www.ofdt.fr/BDD/ publications/docs/DCC2017.pdf (cited 23 Aug 2017).

8. Inserm. Alcool et santé. https://www.inserm.fr/thematiques/ neurosciences-sciences-cognitives-neurologie-psychiatrie/dossiersd-information/alcool-et-sante (cited 25 Aug 2017).

9. Holmqvist M, Bendtsen P, Spak F, et al. Asking patients about their drinking. Addict Behav 2008;33:301-14.

10. lid TG, Nesvåg S, Meland E. When general practitioners talk about alcohol: exploring facilitating and hampering factors for pragmatic case finding. Scand J Public Health 2015;43:153-8.

11. Société Française d'alcoologie, 2014. Mésusage de l'alcool : dépistage, diagnostic et traitement. https://www.sfalcoologie.asso.fr/ download/RBP2014-SFA-Mesusage-AA.pdf

12. Franck J, Jayaram-Lindström N. Pharmacotherapy for alcohol dependence: status of current treatments. Curr Opin Neurobiol 2013;23:692-9.

13. C. Garbutt J. Efficacy and tolerability of naltrexone in the management of alcohol dependence. Curr Pharm Des 2010:16:2091-7.

14. Sinclair JMA, Chambers SE, Shiles CJ, et al. Safety and tolerability of pharmacological treatment of alcohol dependence: comprehensive review of evidence. Drug Saf 2016;39:627-45.

15. Goh ET, Morgan MY. Review article: pharmacotherapy for alcohol dependence - the why, the what and the wherefore. Aliment Pharmacol Ther 2017;45:865-82.

16. Higuchi S, Saito T. Reduction in alcohol consumption: therapeutic goal in alcohol dependence treatment]. Nihon Arukoru Yakubutsu lgakkai Zasshi. févr 2013;48:17-31.

17. Paille F, Martini H. Nalmefene: a new approach to the treatment of alcohol dependence. Subst Abuse Rehabil 2014;5:87.

18. Rahhali N, Millier A, Briquet $B$, et al. Modelling the consequences of a reduction in alcohol consumption among patients with alcohol dependence based on real-life observational data. BMC Public Health 2015;15:1271.

19. Probst C, Manthey J, Martinez A, et al. Alcohol use disorder severity and reported reasons not to seek treatment: a cross-sectional study in European primary care practices. Subst Abuse Treat Prev Policy 2015;10:32.

20. Wallhed Finn S, Bakshi AS, Andréasson S. Alcohol consumption, dependence, and treatment barriers: perceptions among nontreatment seekers with alcohol dependence. Subst Use Misuse 2014;49:762-9.

21. Creswell J, Clark PV. Designing and conducting mixed methods research. 2 edn. Thousand Oaks: Sage Publications, 2011.

22. Bohn MJ, Babor TF, Kranzler HR. The Alcohol Use Disorders Identification Test (AUDIT): validation of a screening instrument for use in medical settings. $J$ Stud Alcohol 1995;56:423-32.

23. Mazzonetto AC, Fiates GM. Perceptions and choices of Brazilian children as consumers of food products. Appetite 2014;78:179-84.

24. Marchand P, Ratinaud P. Entre distinctivité et acceptabilité. Réseaux 2017;204:71-95.

25. Protopopescu C, Raffi F, Roux P, et al. Factors associated with nonadherence to long-term highly active antiretroviral therapy: a 10 year follow-up analysis with correction for the bias induced by missing data. J Antimicrob Chemother 2009;64:599-606.

26. Paillé $P$, Mucchielli A. L'analyse qualitative en sciences humaines et sociales. Paris: Armand Colin, 2012:424. 
27. Papastavrou E, Efstathiou G, Tsangari H, et al. Patients' decisional control over care: a cross-national comparison from both the patients' and nurses' points of view. Scand J Caring Sci 2016;30:26-36.

28. Demir YP, Balci NÇ, Ünlüer NÖ, et al. Three different points of view in stroke rehabilitation: patient, caregiver, and physiotherapist. Top Stroke Rehabil 2015;22:377-85.
29. Guix Oliver J, Fernández Ballart J, Sala Barbany J. Patients, physicians and nurses: three different points of view on the same issue. Attitudes to and perceptions of patient rights]. Gac Sanit. déc 2006;20:465-72.

30. Room R. Intoxication and bad behaviour: understanding cultural differences in the link. Soc Sci Med 2001;53:189-98.

31. Gergen KJ, Josselson R, Freeman M. The promises of qualitative inquiry. Am Psychol 2015;70:1-9. 